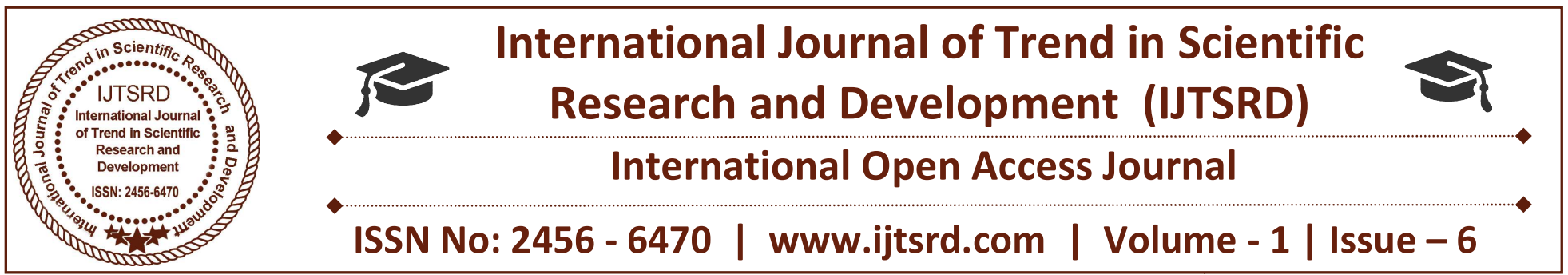

\title{
Vibration Analysis on Car Steering due to Smooth and Rough Road Condition
}

\author{
Mr.Velmurgan \\ M.E,P.h,D.,Department of \\ Mechanical Engineering, Saveetha \\ School of Engineering, Saveetha \\ University, Thandalam, Chennai, \\ Tamil Nadu
}

\author{
M.V.Srikanth \\ Department of Mechanical \\ Engineering, Saveetha School of \\ Engineering, Saveetha \\ University, Thandalam, Chennai, \\ Tamil Nadu
}

\author{
K.Balakrishna \\ Department of Mechanical \\ Engineering, Saveetha School of \\ Engineering, Saveetha \\ University, Thandalam, Chennai, \\ Tamil Nadu
}

\begin{abstract}
In this project actually we are going to find out the vibrational analysis for different car steering for different road profiles. And also our aim is to find out or collecting out the vibrational values, to know the vibration of the steering in different road conditions. In this project we have used the accelerometer sensor for finding out the steering vibrational values in different road profiles. And also we have used the digital to analog converter, which convert the sensor reading values to the analog values.
\end{abstract}

The methodology we have used as usually normal method to taking vibrational values of normal steering and power steering in smooth and rough road conditions. The values we have collected from the sensor readings are put it in the DEWE software for analyzing, in this software can find out which steering will produce more vibration in different road profiles. In this project we are going to find which steering will produce more vibration in different road conditions.

\section{INTRODUCTION}

Cars are generally used for the comfortable journey. The design and testing of a car is so critical that they should ensure both safety and comfort. The design and fabrication of a car is generally divided into eight sub system design. They are
a. Body and frame
b. Wheels and tires
c. Engine
d. Transmission
e. Suspension system
f. Steering system
g. Braking system
h. Ergonomics

After designing a car many tests are done on it before releasing it into the market. Also the tests are done on the vehicles at various stages of manufacturing, developing and using. The common tests on any vehicle are done to ensure that the safety of the vehicle. Tests are done on each above stated system and checked for satisfactory working.

However there are many tests are done to check the comfort levels of the vehicle. Now-a-days it is most important to ensure that different vibrations and noise present in the vehicle must be controlled. For this NVH testing is done on different parts of a vehicle. 


\section{REQUIRED MATERIALS}

\section{a. ACCELEROMETER SENSOR}

An accelerometer is a device that measures proper acceleration. Proper acceleration, being the acceleration (or rate of change of velocity) of a body in its own instantaneous rest frame, is not the same as coordinate acceleration, being the acceleration in a fixed coordinate system. For example, an accelerometer at rest on the surface of the Earth will measure acceleration due to Earth's gravity, straight upwards (by definition) of $\mathrm{g} \approx 9.81 \mathrm{~m} / \mathrm{s} 2$. By contrast, accelerometers in free fall (falling toward the center of the Earth at a rate of about $9.81 \mathrm{~m} / \mathrm{s} 2$ ) will measure zero.

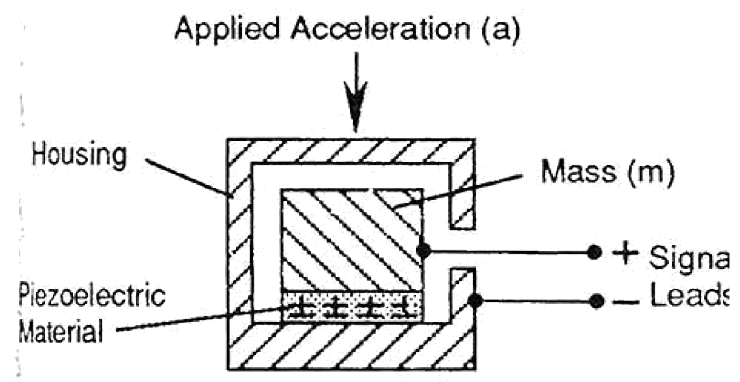

Basic Accelerometer

\section{TYPES OF ACCELEROMETERS:}

1. piezo electric accelerometer

2. seismic type accelerometer

\section{Piezoelectric Accelerometer}

A piezoelectric accelerometer is an accelerometer that employs the piezoelectric effect of certain materials to measure dynamic changes in mechanical variables (e.g., acceleration, vibration, and mechanical shock).

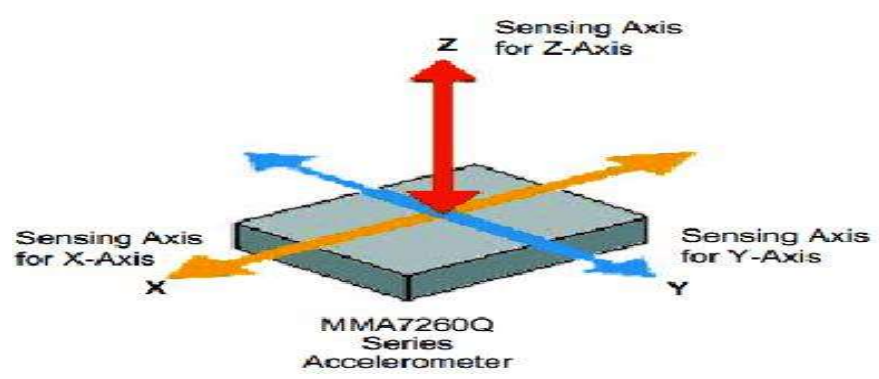

\section{Seismic type Accelerometer}

i. A seismic mass is suspended from the housing of the accelerometer through a spring.

ii. A damper is connected between the seismic mass and the housing of the accelerometer.

iii. The seismic mass is connected to an electric displacement transducer.

Linear Seismic Displacement Sensing Accelerometer

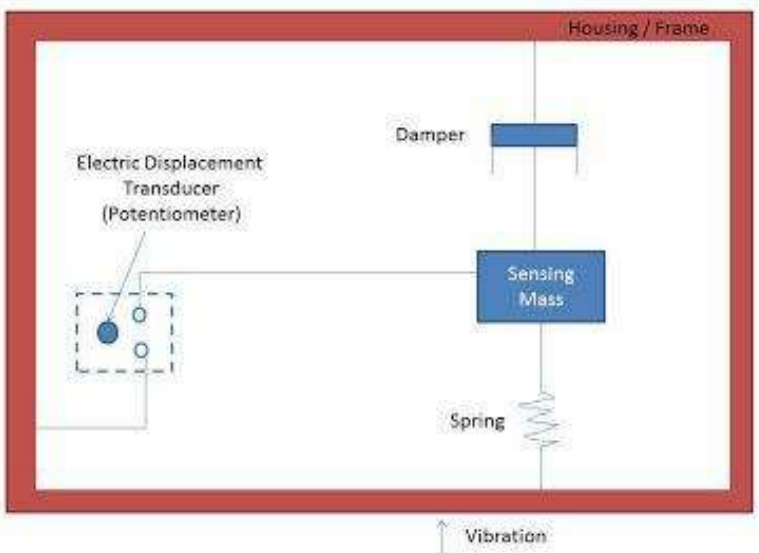

\section{b. ANALOG TO DIGITAL CONVERTER}

In electronics, an analog-to-digital converter (ADC, $\mathrm{A} / \mathrm{D}, \mathrm{A}-\mathrm{D}$, or A-to-D) is a system that converts an analog signal, such as a sound picked up by a microphone or light entering a digital camera, into a digital signal. An ADC may also provide an isolated measurement such as an electronic device that converts an input analog voltage or current to a digital number proportional to the magnitude of the voltage or current.

Typically the digital output is a two's complement binary number that is proportional to the input, but there are other possibilities.

There are several ADC architectures. Due to the complexity and the need for precisely matched components, all but the most specialized ADCs are implemented as integrated circuits (ICs).

A digital-to-analog converter (DAC) performs the reverse function; it converts a digital signal into an analog signal. 


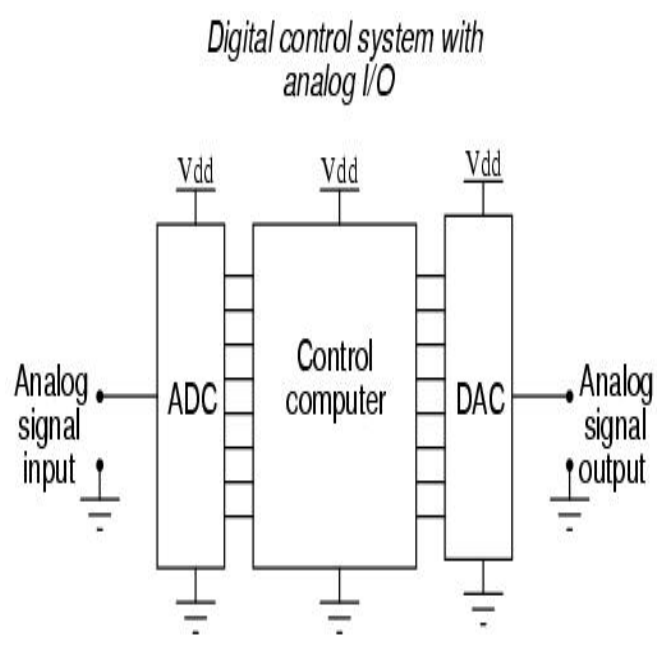

3. LITERATURE REVIEW

1) Zhou Weichao et al emphasis about the affect of duel fan cooling system on the steering wheel vibrations. A dual-fan cooling system is widely used for modern automobiles to cool down engine and air conditioner. Beating-vibration problem on steering wheel due to the cooling fan system is a serious problem, especially as the cabin compartment becomes more comfortable. This paper presents a study related to the beating vibration generation mechanisms, sources, and transfer paths.

2) Fu Lin Zhen studied the issues of cooling fan and tire and suggested a method by adjusting the fan's speed and dynamic imbalance to control beatingvibration. Atsushi Suzuki [3] analyzed cooling fan noise by transient analysis. In this [4] discussed about the vibrations transmitted from the steering wheel of the tractor with a 2-wheel drive to the driver's hands.

3) Ahmed Abd Ali Hamid et al presents about the research results of the vibration transmitted from the steering wheel of the tractor with a 2-wheel drive to the driver's hands. They conducted the vibration measurements were carried out on the tractor randomly chosen from the collage of agriculture / university of Baghdad. Before testing the tractor was examined and adjusted following the producer's recommendations.

\section{METHODOLOGY}

Generally, automobile frame and the body can be supported by suspension. Besides that the suspension mechanism is allowing the wheels to "soak up" wrong-doing on the road surface. The consequence is the wheels will tend to stay in contact with the road, and the passengers of the vehicle enjoy a ride that is protected from road shock.

The front suspension need to focus on support the weight of the front end of the vehicle, absorb road shocks and cushion the passengers and load against those shocks, provide steering control and alignment and maintain steering control during severe braking. Notionally, if a road were perfectly flat, with no abnormality, suspensions wouldn't be necessary. Unfortunately, roads are far from flat. Without suspension, a motor vehicle travelling at today speeds would not only be uncomfortable, it would be virtually uncontrollable. Steering wheel vibrations are noticed when vehicle speed changes, as when starting out from a stop, passing, and slowing down or coasting

The perception of ride quality is corrupted by virtually any disturbance experienced by the drivers or passengers. Human sensitivity varies according to the nature of the disturbance. Therefore, a good Ride not just depends on the overall design of the vehicle, but also the design of the suspension system. Even freshly Paved highways have understated imperfections that can interact with the wheels of a car.

Instead of carry the load from engine compartment, different road condition will gives different outcomes for the front suspension system. The front suspension system was designated to perform at certain range of vibration.

Yet the drivers and passengers, certain of them not only used the vehicle on the smooth road but then on the various kind of road which sometimes the front suspension does not perform on that kind of road. Thus, the project will investigate the benchmarking of steering wheel vibrations on passenger car.

\section{i. Causes for vibrations in steering wheel:}

1. The most common reason for a car to shake is related to tires. If the tires are out of balance then the steering wheel can shake. This shaking starts at around 50-55 miles per hour (mph). It gets worse around $60 \mathrm{mph}$ but starts to get better at high speeds. 
2. Sometimes brake rotors can be the cause of shaking. If your steering wheel shakes while you are braking then the problem could be caused by "out of round" brake rotors. This vibration can also be felt through your brake pedal.

3. Another common problem that can cause shaking is when a brake caliper sticks on. When this happens you will experience a vibration through the steering wheel starting at 45 to 50 miles per hour. It will get very bad the faster you go, and you will also smell a burning odour when you stop.

\section{EXPERIMENTAL SET UP}

The tests required for the vibration characterization, are explained and various equipment used for the experiments are illustrated. Accelerometer sensors are usually used for the vibration measurement, because of their reliability and accuracy. Various sensors used for the vibration measurement are clearly explained in the introduction.

The vibrations may present in three directions. In a steering wheel the main concentration is in only two directions. They are in the vehicle longitudinal direction and vertical direction. The vibrations present in the transverse direction will be more affective and causes mis-steering. Due to the manufacturing defects this may occur. For market release car this will not be present in the car.

1. In the vehicle longitudinal direction, these are caused by braking and acceleration forces.

2. In vertical direction to road, these are caused by the transmission of road roughness to the steering.

The engine vibrations may contribute to both the cases. In the lateral direction, is even termed as steering play and is due to improper placement of steering parts. (Manufacturer should correct these immediately).
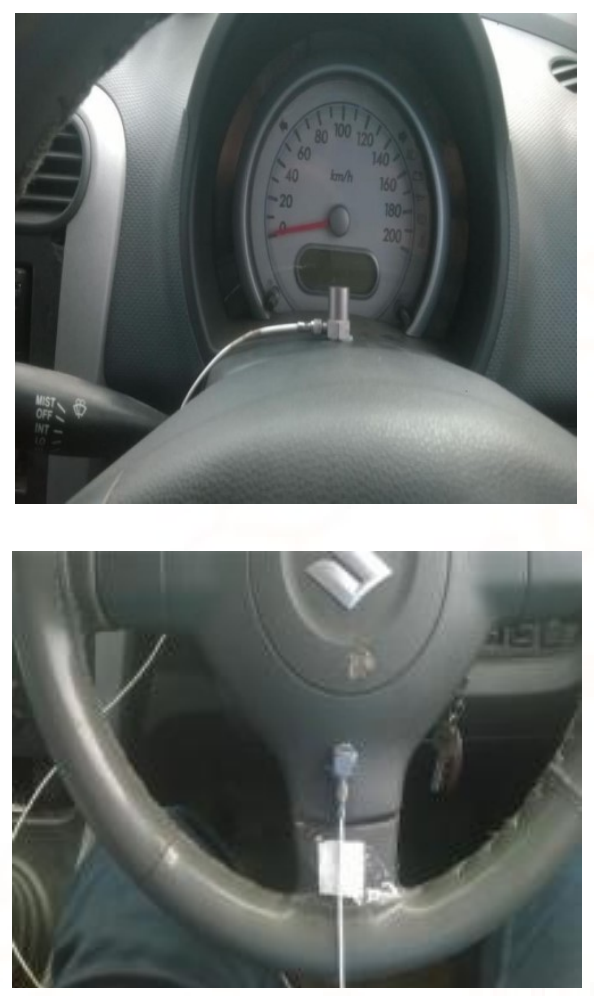

\section{6. 'DEWE' software:}

DEWESoft is measurement software which can acquire data from much different measurement hardware and enables the user to do processing, storage and analysis in a simple way. The main idea of DEWESoft is to have two modes of operation: Acquisition and Analysis. The main difference is that Acquisition part works with a real hardware while Analysis works with stored file. But same math processing and visualization can be applied either during measurement or also on stored files. Therefore the parts of the manual describing the Measurement are valid also for analysis.

\section{SOFTWARE APPLICATIONS}

On-road testing=Brake Test, Pass by Noise, Vehicle Dynamics, ADAS and

Drive Machine Monitoring, Lighting, Equipment.

Durability Testing= $\mathrm{Road}$

Load Data, Stress-Strain Analysis, Fatigue Analysis, DSA possibilities.

Power train and E-Mobility = Combustion Analysis, Rotation and Vibration, E-Mobility, Power Measurement possibilities. 


\section{RESULT AND DISCUSSION}

Using the accelerometer sensors the vibrations are measured with their acceleration (in terms of ' $\mathrm{g}$ '). From this acceleration signal over time it is required to calculate the amplitude of the wave form i.e. nothing but displacement. For this purpose the mathematical tools like IIR filters in the DEWESOFT are used where double integration is done to the entire wave form. For each condition the observed vibration signal is represented in two domains that are in Time Domain signal of representing Amplitude over the time and in Frequency Domain signal of representing Amplitude over the Frequency

\section{Indica at $20 \mathrm{Km}$ speed}

$(\mathrm{g})$

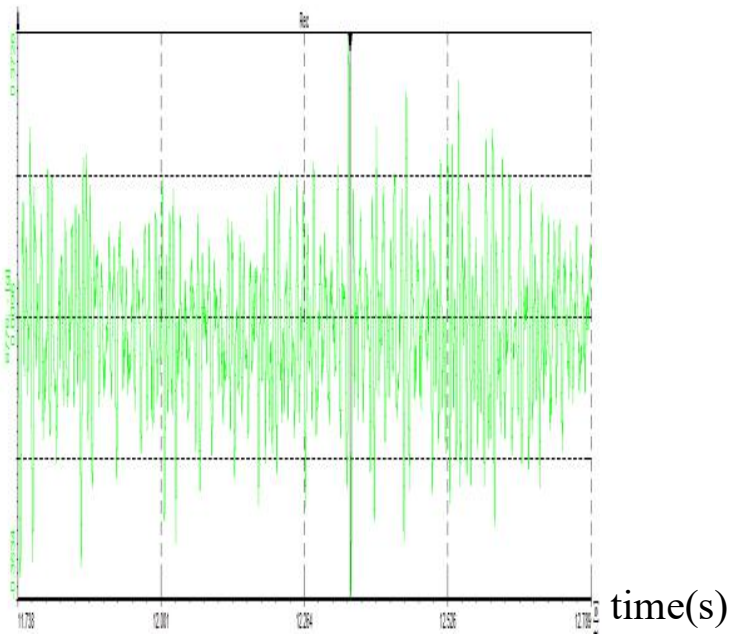

\section{Chart Title}

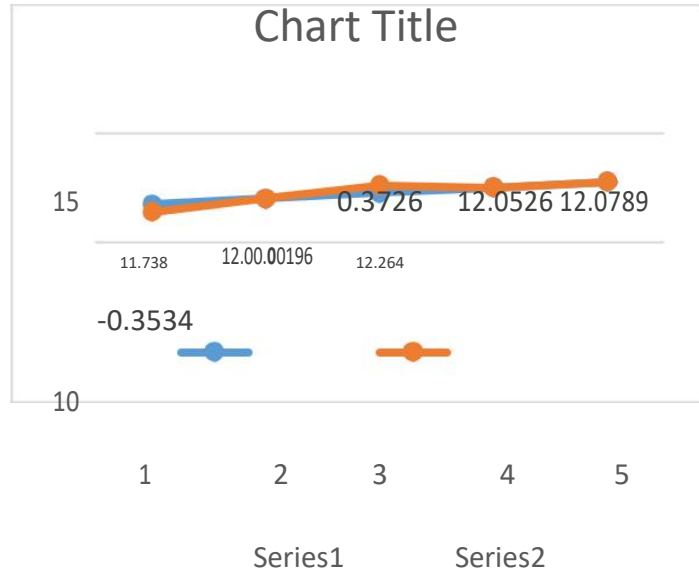

\section{Etios at 20km speed}

(g)

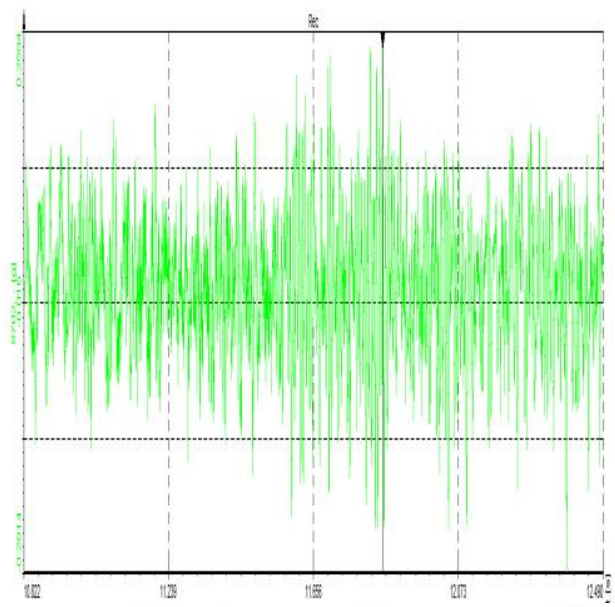

Time

\section{Analysis of steering vibration}

Vibration of different speed

\begin{tabular}{|r|l|l|}
\hline \multicolumn{1}{|c|}{ SPEED } & INDICA & ETIOS \\
\hline $\mathbf{2 0}$ & $0.37(\mathrm{~g})$ & $0.25(\mathrm{~g})$ \\
\hline $\mathbf{4 0}$ & $1.14(\mathrm{~g})$ & $0.43(\mathrm{~g})$ \\
\hline $\mathbf{6 0}$ & $0.81(\mathrm{~g})$ & $0.70(\mathrm{~g})$ \\
\hline $\mathbf{8 0}$ & $2.18(\mathrm{~g})$ & $1.65(\mathrm{~g})$ \\
\hline
\end{tabular}

\section{GRAPH}

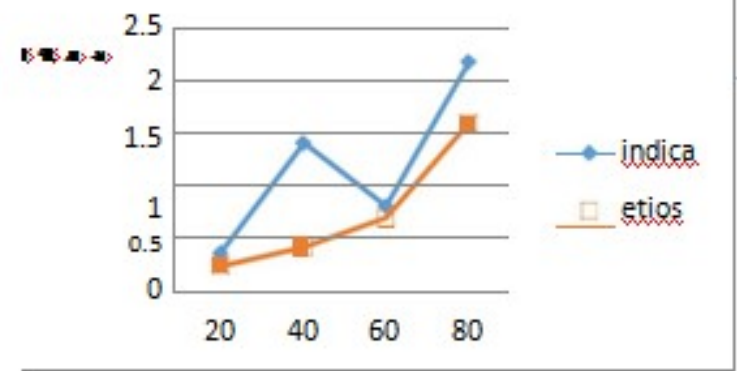




\section{Vibration for different conditions}

\begin{tabular}{|c|c|c|}
\hline CONDITIO & INDIC & ETIO \\
\hline $\mathbf{N}$ & $\mathbf{A}$ & $\mathbf{S}$ \\
\hline Rough road & $1.14(\mathrm{~g})$ & $0.43(\mathrm{~g})$ \\
\hline Smooth road & $0.81(\mathrm{~g})$ & $0.70(\mathrm{~g})$ \\
\hline Gravel road & $2.18(\mathrm{~g})$ & $1.65(\mathrm{~g})$ \\
\hline
\end{tabular}

\section{GRAPH}

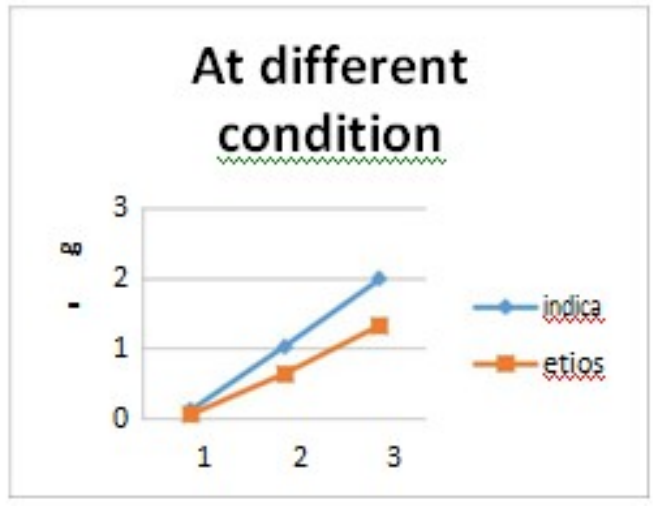

\section{CONCLUSION}

In this project we have found out the vibration of normal steering and power steering for different road conditions. We have collected the sensor values and analyze the values in DEWE software to find out which vehicle steering is producing more vibration. And in this project we found that the normal steering is producing more vibration and power steering is producing less vibration.

In this project if we implement some new technologies like hydraulic steering and vacuum steering we can reduce some more vibration in different road profiles.

\section{REFERENCES}

1) Stephan Milosavljevic, Frida Bergman , Borje Rehn, Allan B. Carman "All-terrain vehicle use in agriculture: Exposure to whole body vibration and mechanical shock "Elsevier, Applied Ergonomics, 41 (2010) pp.530-535.

2) ISO 2631-1 Second Edition 1997 - Mechanical Vibration and Shock - Evaluation of Human Exposure to Whole Body Vibration.
3) Rebecca Wolfgang, Robin Burgess-Limerick "Whole-body vibration exposure of haul truck drivers at a surface coal Mine" Elsevier,Applied Ergonomics, 45 (2014) pp. $1700-1704$

4) Ornwipa Thamsuwan Ryan P. Blood, Randal P. Ching, Linda Boyle , Peter W. Johnson "Whole body vibration exposures in bus drivers: A comparison between a high-floor coach and a lowfloor city bus" International Journal of Industrial Ergonomics, 43 (2013) pp.9- 17

5) Harris, C. M., "Shock and Vibration Handbook", 5 thEdition, McGraw Hill Pub.,New York, pp. 44.1-20

6) Jaimon Dennis Quadros, Suhas, Vaishak N.L, Shilpa. B "Study of vibration and its effects on health of a two wheeler rider" IJRET,Volume2,Issue 08 | Aug-2013

7) Gourav.P.Sinha, P.S.Bajaj "Vibration analysis of hero honda vehicle" IJMPE,Volume-2, Issue 2 Feb-2014

8) Vikas Kumara, V.H. Saranb and Veeresalingam Guruguntla " Study of Vibration Dose Value and Discomfort due to Whole Body Vibration Exposure for a Two Wheeler Drive" Proc. of the 1st International and 16th National Conference on Machines and Mechanisms (iNaCoMM2013), IIT Roorkee, India, Dec 18-20 2013

9) Hsieh-Ching Chen, Wei-Chyuan Chen , YungPing Liu, Chih-Yong Chen, Yi-Tsong Pan "Whole-body vibration exposure experienced by motorcycle riders - An evaluation according to ISO 2631-1 and ISO 2631-5 standards" International Journal of Industrial Ergonomics, 2009, pp. 708-178 